\title{
(6) OPEN ACCESS \\ UK guideline on transition of adolescent and young persons with chronic digestive diseases from paediatric to adult care
}

- Additional material is published online only. To view please visit the journal online (http://dx.doi.org/10.1136/ gutjnl-2016-313000).

For numbered affiliations see end of article.

Correspondence to Dr James 0 Lindsay, Bart's Health NHS Trust, The Royal London Hospital, London E1 1BB, UK; James.Lindsay@ bartshealth.nhs.uk

*Brooks and Smith are joint first authors.

Received 5 September 2016 Revised 10 January 2017 Accepted 24 January 2017 Published Online First 20 February 2017
CrossMark

To cite: Brooks AJ, Smith PJ, Cohen $\mathrm{R}$, et al. Gut 2017;66:988-1000.

\author{
Alenka J Brooks, ${ }^{1 *}$ Philip J Smith, ${ }^{2 *}$ Richard Cohen, ${ }^{3}$ Paul Collins, ${ }^{4}$ Andrew Douds, ${ }^{5}$ \\ Valda Forbes, ${ }^{6}$ Daniel R Gaya, ${ }^{7}$ Brian T Johnston, ${ }^{8}$ Patrick J McKiernan, ${ }^{9}$ \\ Charles D Murray, ${ }^{2}$ Shaji Sebastian, ${ }^{10}$ Monica Smith, ${ }^{11}$ Lisa Whitley, ${ }^{12}$ \\ Lesley Williams, ${ }^{13}$ Richard K Russell, ${ }^{14}$ Sara A McCartney, ${ }^{15}$ James 0 Lindsay ${ }^{16,17}$
}

\section{ABSTRACT}

The risks of poor transition include delayed and inappropriate transfer that can result in disengagement with healthcare. Structured transition care can improve control of chronic digestive diseases and long-term health-related outcomes. These are the first nationally developed guidelines on the transition of adolescent and young persons (AYP) with chronic digestive diseases from paediatric to adult care. They were commissioned by the Clinical Services and Standards Committee of the British Society of Gastroenterology under the auspices of the Adolescent and Young Persons (A\&YP) Section. Electronic searches for English-language articles were performed with keywords relating to digestive system diseases and transition to adult care in the Medline (via Ovid), Psyclnfo (via Ovid), Web of Science and CINAHL databases for studies published from 1980 to September 2014. The quality of evidence and grading of recommendations was appraised using the Grading of Recommendations Assessment, Development and Evaluation (GRADE) system. The limited number of studies in gastroenterology and hepatology required the addition of relevant studies from other chronic diseases to be included.

These guidelines deal specifically with the transition of AYP living with a diagnosis of chronic digestive disease and/or liver disease from paediatric to adult healthcare under the following headings;

1. Patient populations involved in AYP transition

2. Risks of failing transition or poor transition

3. Models of AYP transition

4. Patient and carer/parent perspective in AYP transition

5. Surgical perspective

\section{SUMMARY OF RECOMMENDATIONS}

Recommendations: patient populations involved in adolescent and young person transition

We recommend that adolescent and young person (AYP) with IBD, coeliac disease and chronic liver disease should be involved in formal transition arrangements (Grading of Recommendations Assessment, Development and Evaluation (GRADE) recommendation: strong $(\mathrm{C})$ ).

\section{Recommendations: risk of failing or poor AYP transition}

1. We recommend the use of structured transition programmes to improve control of chronic gastrointestinal (GI) disease in AYP (GRADE recommendation: strong $(\mathrm{C})$ ).

2. We recommend the use of structured transition programmes to enhance adherence to medications, clinic attendance and clinical outcomes including organ survival in liver transplantation (GRADE recommendation: strong (C)).

3. We suggest that the use of structured transition programmes may increase disease related knowledge in patients and carers/parents (GRADE recommendation: weak (C)).

4. We suggest that a structured transition programme may improve psychological outcome and health-related quality of life in chronic GI diseases (GRADE recommendation: weak (D)).

5. We suggest that the use of a structured transition programme may reduce adverse outcomes such as hospitalisation, surgery and radiation exposure in GI disease (GRADE recommendation: weak $(\mathrm{C})$ ).

Recommendations: models of AYP transition

1. We suggest that an overlap with both paediatric and adult gastroenterology care is a core element of every structured transition service (GRADE recommendation: weak (C)).

2. We suggest that while there are numerous models of transition there is no evidence to support a particular type (GRADE recommendation: weak (C)).

3. We recommend an effective transition model may benefit from inclusion of the following elements (GRADE recommendation: strong (D)):

A. Flexible timing of transition

B. A named transition coordinator to oversee the process

C. Individualisation of the transition model based on local expertise, staffing, resources and geography

D. Assessment of readiness for transfer

E. Disease-specific education programme

4. We recommend information technology as an effective and cost-efficient tool to facilitate transition (GRADE recommendation: strong (C)).

5. We recommend that AYP's self-efficacy is enhanced by the use of virtual intervention and electronic communication (GRADE recommendation: strong (C)).

6. We recommend regular audit of the transition service in order to improve the service, 
outcomes and assess key performance indicators (GRADE recommendation: strong (D)).

\section{Recommendations: patient and carer/parent perspective in AYP transition}

1. We suggest that healthcare professionals (HCPs) consider concerns of AYP and their carers/parents during transition and identify when additional emotional and psychological support is required (GRADE recommendation: weak (D)).

2. We suggest that HCPs maintain the goal of empowering the AYP to become independent while acknowledging the carer/ parent perspectives (GRADE recommendation: weak (C)).

3. We recommend that AYP identified as at risk of nonadherence may benefit from targeted specific educational and organisational interventions (GRADE recommendation: strong $(\mathrm{C})$ ).

4. We recommend that disease-specific information and education be appropriate for the AYP developmental stage and this should be reassessed over the period of transition (GRADE recommendation: strong (C)).

5. We suggest the transition process addresses the AYP's lifestyle, future health concerns, educational/employment goals, psychosocial health, sexuality and reproduction (GRADE recommendation: weak (D)).

\section{GUIDELINE DEVELOPMENT} Introduction

The requirement for the consensus guidelines on this topic was highlighted by a national survey of physician and nurse attitudes to transition conducted by the Adolescent and Young Persons (AYP) Section of the British Society of Gastroenterology (BSG). ${ }^{1}{ }^{2}$ There is currently no European consensus guideline available for clinicians working in this field, although in 2015 the Italian Societies of Gastroenterology published a position statement, ${ }^{3}$ as have the North America Society for Paediatric Gastroenterology, Hepatology and Nutrition in 1993. ${ }^{4}$ The guideline proposal was reviewed and accepted by the Clinical Services and Standards Committee (CSSC) in 2014. Members of the guideline committee were selected after an open invitation for expressions of interest and divided into multidisciplinary subgroups. The authors drafted a preliminary guideline document following the 'BSG Guideline Advice' document. ${ }^{5} 6$ The draft guidelines were submitted for review by BSG AYP Section, CSSC and BSG Council and revised in response to their comments.

\section{Data sources and search strategy}

A systematic literature search was undertaken by a medical librarian (RF) using four relevant databases, Medline (via Ovid), Embase, Web of Science and CINAHL, aiming to capture all relevant studies across disciplines including paediatric and adult gastroenterology from 1980 to September 2014. MeSH search terms relating to digestive system diseases ("gastrointestinal disease", "hepatological disease", "liver disease", "digestives system disease"), transition to adult care ("transition clinic", "transition"* "transition process", "transition care”, "transfer”), adolescent ("adolescen"*, "young adult"* (were entered and combined, and limited to 'adolescent' and 'young adult' (see online supplementary appendix 1)). Following this, section working groups reviewed all relevant articles and any additional records identified through other sources in an iterative way, drawing on clinical expertise in the field to draw on key publications related to AYP transition in non-GI or hepatology disorders.

*Denotes terms where truncation has been used.

\section{Study eligibility and selection criteria}

Members of the guideline group determined study eligibility for inclusion in the final consensus. Studies were initially screened independently by all members of each subgroup. Decisions regarding study inclusion were made by consensus within each subgroup, with final decisions regarding study inclusion made by the relevant chair. Studies were included if (a) published in full and (b) written in English. Studies were excluded if (a) they were case studies or not empirical studies (eg, narrative reports) and (b) they were only published in abstract. Additional studies of interest were identified by hand searches of bibliographies and cited references and by consultation with clinical experts in the field.

\section{Data extraction and quality assessment}

Of 639 studies identified, a formal assessment of quality was conducted using the GRADE system. ${ }^{78}$

\section{Assessing the quality of the guidelines: the Agree II instrument}

The Agree II instrument is the recognised and accepted method of assessing the quality of clinical guidelines. 9 Six domains are listed and the position of the current guideline in these domains is stated:

\section{Scope and purpose}

The aim of the guideline is to provide clinical guidelines based on current available literature for the care of AYP as they progress from paediatric health services through to adult care, for clinicians and other health professionals in gastroenterology and hepatology.

2. Guideline development group membership and stakeholder involvement

Membership of the guideline development group included paediatric and adult gastroenterologists and hepatologists, specialist nurses and dieticians who were selected after an open call for participation was published in the BSG newsletter. The group also included patient and parent members as well as representatives from appropriate patient organisations who were invited to participate by the chairperson. The guideline development group had three face-to-face meetings (30 September 2014, 20 January 2015 and 5 May 2015) where the scope and remit of the guideline was planned and progress reviewed at key stages. The guideline development group was divided into four multidisciplinary subgroups; patient populations, risks of poor transition, models of transition and, finally, the patient and parent perspective (see online supplementary appendix 2). Each subgroup had a nominated chairperson (RKR, DRG, SS and PJS, respectively) with the responsibility of overseeing the review of relevant literature and production of draft recommendations and accompanying text for publication for that section (see online supplementary appendix 2).

\section{Rigour of development}

The guideline development group met regularly for discussion via face-to-face meetings and teleconferences during the period from September 2014 to September 2015. The guidelines rely on a formal assessment of study quality that was conducted using the GRADE system. ${ }^{78}$ GRADE was used to determine (a) quality of studies included into high (A), moderate (B), low (C) or very low (D); and (b) assess guideline recommendations and classify them as either STRONG or WEAK (tables 1 and 2). In the guideline, we have stated the recommendations and the associated GRADE of evidence together. Practice points were included based on expert clinical experience and consensus of opinion rather than these being supported by clinical research, as used in European Crohn's and Colitis Organisation (ECCO) 
Table 1 Individual studies included in the guideline are formally assessed using the GRADE system ${ }^{1}$ with the quality of the body evidence rated, from 'high' (A) to 'very low' (D)

\begin{tabular}{|c|c|c|c|c|}
\hline \multirow[b]{2}{*}{ Study design } & \multirow{2}{*}{$\begin{array}{l}\text { Initial quality of a body of } \\
\text { evidence }\end{array}$} & \multicolumn{2}{|c|}{ Modify the initial quality of a body of evidence } & \multirow{2}{*}{$\begin{array}{l}\text { Quality of body } \\
\text { of evidence }\end{array}$} \\
\hline & & Rate lower if & Rate higher if & \\
\hline \multirow[t]{2}{*}{ Randomised controlled trials } & $\operatorname{High} \star \star \star \star$ & $\begin{array}{l}\text { Risk of bias } \\
-1 \text { Serious } \\
-2 \text { Very } \\
\text { serious }\end{array}$ & $\begin{array}{l}\text { Large effect } \\
+1 \text { Large } \\
+2 \text { Very large }\end{array}$ & $\operatorname{High}(\mathrm{A}) \star \star \star \star$ \\
\hline & & $\begin{array}{l}\text { Inconsistency } \\
-1 \text { Serious } \\
-2 \text { Very } \\
\text { serious }\end{array}$ & $\begin{array}{l}\text { Dose response } \\
+1 \text { Evidence of a gradient }\end{array}$ & $\begin{array}{l}\text { Moderate } \\
\text { (B) } \star \star \star\end{array}$ \\
\hline \multirow[t]{3}{*}{$\begin{array}{l}\text { Observational studies/qualitative } \\
\text { studies }\end{array}$} & Low $\star \star$ & $\begin{array}{l}\text { Indirectness } \\
-1 \text { Serious } \\
-2 \text { Very } \\
\text { serious }\end{array}$ & All plausible residual confounding & \\
\hline & & $\begin{array}{l}\text { Imprecision } \\
-1 \text { Serious } \\
-2 \text { Very } \\
\text { serious }\end{array}$ & +1 would reduce a demonstrated effect & Low $(C) \star \star$ \\
\hline & & $\begin{array}{l}\text { Publication } \\
\text { bias } \\
-1 \text { Likely } \\
-2 \text { Very likely }\end{array}$ & $\begin{array}{l}+1 \text { would suggest a spurious effect if no effect } \\
\text { observed }\end{array}$ & Very low (D) $\star$ \\
\hline
\end{tabular}

Table 2 Guideline recommendations are classified as either strong or weak by determining the balance of desirable and undesirable outcomes using the GRADE system ${ }^{1}$

\begin{tabular}{|c|c|}
\hline \multicolumn{2}{|c|}{$\begin{array}{l}\text { Rating the strength of a recommendation: balancing desirable and } \\
\text { undesirable outcomes }\end{array}$} \\
\hline Strong recommendation & Weak recommendation \\
\hline $\begin{array}{l}\text { Desirable outcomes }+++>\text { undesirable } \\
\text { outcomes }+ \\
\text { Examples of desirable outcomes } \\
\text { Increased longevity } \\
\text { Reduction in morbid events } \\
\text { intervention designed to prevent } \\
\text { Resolution of symptoms } \\
\text { Improved quality of life } \\
\text { Decreased resource use }\end{array}$ & $\begin{array}{l}\text { Desirable outcomes }++> \\
\text { undesirable outcomes }+ \\
\text { Examples of undesirable outcomes } \\
\text { Decreased longevity } \\
\text { Immediate serious } \\
\text { complications } \\
\text { Short-term relatively minor side } \\
\text { effects } \\
\text { Long-term rare serious adverse } \\
\text { events } \\
\text { Impaired quality of life } \\
\text { Inconvenience/hassle } \\
\text { Increased resource use }\end{array}$ \\
\hline
\end{tabular}

and European Society for Paediatric Gastroenterology, Hepatology and Nutrition (ESPAGHAN) guidelines. ${ }^{10} 11$

Face-to-face meetings were held to agree the recommendations. Areas of disagreement about the recommendation grade were subject to discussion and, where necessary, voting by members of the guidelines group with consensus achieved when $>80 \%$ were in agreement. Practice points were used where formal recommendations were not possible due to a paucity of appropriate research, but where the guideline development group felt there was enough expert clinical experience and consensus for these to be included. The guidelines were subject to peer review by the CSSC and BSG Council for consideration of publication in July 2016. This involved five expert reviewers providing detailed feedback to the Guideline Development Group. The review resulted in the writing committee (AJB, PJS, JOL, SAM) undertaking changes and improvement in the structure and content of the guideline that underwent subsequent approval by the Chair of the CSSC. The updated guideline was reviewed by all members of the Guideline Development Group prior to submission for publication in September 2016.

4. Clarity and presentation

Recommendations are intended to be specific to particular areas of transition and the process of transition in order to provide clinicians and allied health professionals with guidance to facilitate development of transition facilities with a local setting and context.

\section{Applicability}

Within the guidance we have discussed organisational changes that may be required to apply the recommendations and identified areas suitable for monitoring, audit and service improvement.

6. Editorial independence and conflict of interest

Guideline group members have declared any conflicts of interest, which are detailed at the end of the guideline.

\section{PATIENT POPULATIONS INVOLVED IN AYP TRANSITION Transition for GI disease areas}

Until recently, there has been a lack of transition services for AYP patients with chronic GI and liver diseases in the UK. ${ }^{1} 1213$ The most frequent GI areas where transition arrangements exist are IBD followed by chronic liver disease comprising both transplanted and non-transplanted patients. A very small number of patients with complex nutritional needs are transferred or transitioned on an ad hoc basis although there are not dedicated clinics for these patient groups in the UK. Until recently, the majority of patients with coeliac disease and other common GI illnesses (constipation, GORD), together with simple functional GI disorders, have been transferred from paediatric to adult care or discharged from paediatric care with the expectation that the primary care physician will refer to an appropriate adult consultant if required. However, after the initial evidence search for this guideline was completed in 2016 the first consensus guidelines regarding transition in coeliac disease recommend structured transition for this patient group, ${ }^{14}$ and there has been recent interest in transition 
care for emerging diseases like eosinophilic oesophagitis ${ }^{15}$ and complex functional GI disorders.

\section{Prevalence of GI disease in this population}

While published data exist on the prevalence of specific GI and liver disease in AYPs, the actual numbers of patients who move from paediatric to adult care with or without transition annually have not been recorded systematically. This is important as it will determine the potential impact of recommendations to implement a transition service for a specific disease. An estimate based on extrapolation from audits, surveys or expert opinion is provided in table 3 . Due to the comparatively larger sizes of the patient populations-transition has to date been more frequently undertaken in the IBD and liver disease patient populations, but is of increasing importance in other GI diseases such as coeliac disease ${ }^{14}$ and in complex functional GI disorders. However, the true requirement for transition care among AYP with GI disease has still to be accurately defined and data on the number of transition clinics currently supporting AYPs through the transition process are not available to be able to estimate any shortfall in service provision. However, these figures are likely to be underestimating the true prevalence of AYPs requiring formal transition into adult services. The demand for specialist nutrition for paediatric GI and surgical disorders has risen in recent years, suggesting that increasing numbers of AYP patients may survive and require transition to adult services. Furthermore, the number of complex enteral nutrition patients will be significantly higher than those requiring parenteral nutrition support. Children with complex motility disorders will make up a small proportion of these patients ${ }^{16}$ and therefore may require formal transitioning into adult care with multidisciplinary support given their symptomatology, nutrition support and psychological comorbidity can be difficult to manage.

\section{Disease course and differences between AYP and adults}

For specific GI diseases, there are documented variations in prognosis and clinical course when the disease presents in childhood compared with adulthood. This has clear relevance for the AYP transition process in these diseases. There are also clear differences in diagnostic and therapeutic IBD management dependent on age at diagnosis with a higher use of exclusive enteral nutrition in children with Crohn's disease and general anaesthetic use for endoscopy in children compared with sedation in adults. Furthermore, children presenting with IBD have a more extensive disease phenotype and rapid early progression, although there no clear differences reported in the rate of disease complications. ${ }^{19}$

Although the clinical course of coeliac disease presenting in childhood is often more severe than that presenting later in life, it is difficult to predict outcomes dependent on age at diagnosis with sparse research in this area. There are no studies that assess the benefit or risk of good versus poor disease control during the transition from paediatric to adult care. However, there are differences in management as in children the diagnosis of coeliac disease is often based on serology with supportive investigations without the need for duodenal biopsy, whereas histological evaluation is always recommended in adults. ${ }^{20}$ The use of psychological management for functional GI illness in paediatrics is higher than adult practice. Outside the GI tract, the most common indication for liver transplant in children is for congenital reasons (biliary atresia) compared with acquired liver disease in adulthood.

\section{Recommendations and practice points}

We recommend that AYP with IBD, coeliac disease and chronic liver disease should be involved in formal transition arrangements (GRADE recommendation: strong (C)).

\section{Practice points}

- AYP with other chronic GI and liver conditions, including complex functional disorders, are likely to benefit from formal transition arrangements and may be incorporated into existing transition services.

- HCPs involved in the management of AYP should be aware of the differences between classification, diagnostic methods, treatment and natural history of relevant paediatric and adult chronic GI and liver diseases dealt with in transition clinics.

- Centres should audit their population of AYP with chronic GI and liver diseases to determine the prevalence and service requirements for transition.

Table 3 The estimated (and extrapolated) UK prevalence of chronic paediatric GI/liver conditions and number of patients transitioned each year using the best available epidemiological, audit and survey data as well as expert opinion

\begin{tabular}{|c|c|c|}
\hline GI/liver condition & $\begin{array}{l}\text { UK paediatric prevalence (total population or } \\
\text { proportion within populations) }\end{array}$ & $\begin{array}{l}\text { Estimated number of patients transitioned } \\
\text { per year }\end{array}$ \\
\hline IBD* & 7000 & 1000 ( 60\% Crohn's disease) \\
\hline Chronic liver disease & $\begin{array}{l}\text { The prevalence of paediatric liver disease in } \\
\text { England between } 2008 \text { and } 2014 \text { : } \\
11-15 \text { years: } 1502 \\
16-17: 624 \dagger^{17}\end{array}$ & $\begin{array}{l}\text { Approximately } 61-76 \text { transplant cases per annum } \ddagger^{18} \\
753 \text { paediatric patients were transferred to adult services } \\
\text { between } \\
2008 \text { and 2014) (proportion which are non-transplant is } \\
\text { unknown) } \dagger^{17}\end{array}$ \\
\hline Complex enteral & No relevant data identified & No relevant data identified \\
\hline $\begin{array}{l}\text { Parenteral nutrition (combination of long term in and } \\
\text { out of hospital) }\end{array}$ & $290 \S$ & 60 \\
\hline Coeliac disease & $\begin{array}{l}3-13 \text { per } 1000 \text { children, or approximately } 1: 80 \text { to } \\
1: 300 \text { children }\end{array}$ & 600 per year \\
\hline Allergic/eosinophilic oesophagitis & $\begin{array}{l}\text { Food allergy } 0.6 \%{ }^{4} \\
\text { Eosinophilic oesophagitis } 0.2 \text { per } 100000\end{array}$ & No specific data \\
\hline Functional GI disease & $\sim 10 \%^{5}$ & No specific data \\
\hline
\end{tabular}


- HCPs involved in the management of AYP with chronic GI and liver diseases should receive appropriate training in transition care such as the pitfalls and benefits of transition and strategies to improve transitional care.

- AYPs should be transitioned once they have finished or are in the later stages of puberty. Patients with growth issues should be transitioned once the growth issues are resolved.

\section{RISK OF FAILING TRANSITION OR POOR TRANSITION}

Transition to adulthood is a complicated process for most AYP and is particularly so where AYP have chronic illnesses and ongoing health needs. The transition process has increasingly been recognised as covering a vulnerable period where unaddressed healthcare needs may have long-term consequences. ${ }^{21}$

\section{Inadequate transition arrangements and adverse outcomes}

Inadequate transition arrangements have been associated with a number of adverse outcomes over a wide range of medical conditions including diabetes, ${ }^{22}{ }^{23}$ heart disease ${ }^{24}$ and haematological disorders. ${ }^{25}$ These consequences include delayed and inappropriate care, poor communication with AYP and their families, as well as emotional and often financial stress for patients, their families and healthcare systems. Following solid organ transplantation, inadequate transition has been associated with worsening adherence, ${ }^{26}$ increased graft $\operatorname{loss}^{27}$ and higher mortality. ${ }^{26}$ There have been few specific studies in gastroenterology and hepatology, but similar conclusions are emerging. Inadequate transition in IBD is associated with clinic nonattendance and non-adherence with medication, restricted growth potential and an increased likelihood of requiring surgery. ${ }^{28}$ In coeliac disease, inadequate transition arrangements are associated with dietary non-adherence, anaemia and reduced bone density. ${ }^{29}$

As the AYP grows into adulthood, considerations of further education and employment become important. There is some emerging data on the relevance of a coordinated transition during adolescence in chronic disorders, which may have impact on the future work and employment. ${ }^{30} 31$

\section{Benefits of successful transition in other chronic diseases}

There is evidence to support the benefits achieved by successful transition programmes in chronic diseases in various disciplines. For AYP with diabetes, successful transition has been shown to result in improved objective measures of glycaemic control, better engagement with screening programmes, improved outpatient attendance and engagement with adult providers in addition to decreased hospitalisation with diabetic ketoacidosis. ${ }^{32-35}$

In juvenile idiopathic arthritis and congenital heart disease, successful transition was associated with improved selfknowledge and improved disease knowledge among parents and carers. These were accompanied by increased satisfaction with the process and better quality of life. ${ }^{36}{ }^{37}$ In renal diseases, an integrated paediatric-adult clinical transition service was associated with a striking reduction in the rate of graft loss among the patients with renal transplants. ${ }^{38}$

Evidence to document the impact of successful transition in gastroenterology and hepatology is more sparse. A recent UK study in 72 patients (diagnosed with IBD in paediatric care and then transferred to adult care service) who either went through a formal transition programme versus no formal programme has shown that establishment of a transition programme resulted in improvements in drug adherence, clinical attendance and growth with a reduced need for surgical intervention on retrospective analysis of their medical records. ${ }^{28}$ The same study also showed a trend towards improved growth pattern in the transition patients. A French group that performed a retrospective survey in 48 AYPs who had been transitioned from paediatric to adult care showed that a structured transition programme results in improved patients and carer satisfaction. ${ }^{39}$ Another study in which 81 AYPs with a chronic illness (34 IBD, 13 cystic fibrosis and 34 type 1 diabetes mellitus) were randomised to either a 2-month web-based text delivered health educational programme or a control group that received written materials health-related topics to read has shown disease management, health-related self-efficacy (one's belief in one's ability to accomplish a specific health-related task) and patient-initiated communications were all improved by the use of a generic disease management tool. ${ }^{40}$

\section{Recommendations}

We recommend the use of structured transition programmes to improve control of chronic GI disease in AYP (GRADE recommendation: strong $(\mathrm{C})$ ).

We suggest that the use of structured transition programmes may increase disease related knowledge in patients and carers/ parents (GRADE recommendation: weak (C)).

We suggest that a structured transition programme may improve psychological outcome and health-related quality of life in chronic GI diseases (GRADE recommendation: weak (D)).

We suggest that the use of a structured transition programme may reduce adverse outcomes such as hospitalisation, surgery and radiation exposure in GI disease (GRADE recommendation: weak (C)).

\section{Improvements in adherence and compliance}

Following liver transplantation non-adherence to immunosuppression is a major cause of graft loss and mortality. ${ }^{26}{ }^{41}$ Non-adherence increases throughout adolescence and may worsen when transfer is complete. ${ }^{26}$ The use of a dedicated transplant coordinator results in better adherence and improved self-management of healthcare needs. Thus, AYPs who had moved from paediatric to adult care after liver transplant with the support of a liver transplant coordinator had more appropriate tacrolimus levels and enhanced healthcare management parameters compared with a historical comparison group. ${ }^{42}$ Medication adherence in IBD also appears to be increased following a structured transition programme. ${ }^{28}$

\section{Recommendation}

We recommend the use of structured transition programmes to enhance adherence to medications, clinic attendance and clinical outcomes including organ survival in liver transplantation (GRADE recommendation: strong $(\mathrm{C})$ ).

\section{MODELS OF AYP TRANSITION}

The implementation of existing AYP transition models vary with differences in approach and outcome dependent on coordination between the relevant HCPs. Various models have been proposed and evaluated, but it remains unclear which transition model is associated with the best outcomes for AYP. ${ }^{43}$

\section{Combined care during transition}

Surveys of different transition programmes in a variety of medical disciplines have reported that combined clinic visits with input from both paediatric and adult HCPs are clinically beneficial and endorsed by patients. However, the exact format of transition may be highly variable and may include combined 
adult/paediatric clinics and/or joint multidisciplinary clinics or 'virtual' transition clinics. ${ }^{44}$

\section{Recommendation}

We suggest that an overlap between paediatric and adult gastroenterology care is a core element of every structured transition service (GRADE recommendation: weak (C)).

\section{Benefit from AYP transition clinics in GI/liver diseases}

Transition models incorporating a joint paediatric-adult clinic that have been associated with improvements in clinically relevant endpoints have been reported sparsely in gastroenterology and hepatology but there is supporting evidence from other chronic diseases that affect AYPs. For example in patients with renal transplant, a transition model in which the use of a single referral letter for transfer was replaced by an integrated paediatric-adult clinical service was associated with a reduction in the rate of graft loss. ${ }^{38}$ However, no significant enhancement of adherence, patient satisfaction or clinician's subjective assessment of graft stability was reported in another small study of renal transplant recipients. ${ }^{45}$ In type 1 diabetes, significant improvements in $\mathrm{HbA} 1 \mathrm{c}$, rate of screening for complications of the disease and attendance at clinic appointments have been described in patients undergoing a structure transition planned and coordinated with the adult team compared with those in whom a letter of referral was used to transfer patients to the adult services. $^{32}$

In a single-centre study from the UK where the transition clinic involved use of combined clinics with paediatric and adult gastroenterology teams and using assessment of readiness to transfer using tools, there were indicators for improvement in clinically relevant outcomes such as adherence, surgery rates and growth and development. ${ }^{15}$ In a further study from France, the majority of patients attending a joint paediatric and adult IBD clinic view a joint clinic as being beneficial in transferring information from their medical records and in building confidence in their new adult physician. ${ }^{39}$

\section{Different transition models}

The published guidance for specific models of transition lacks a strong evidence base and originates from expert opinion as a result of weak studies involving small patient numbers, bias and multiple methodological flaws within the data sets. ${ }^{32} 444647$

However, a theoretical framework, entitled the Chronic Care Model (CCM), describes how teams comprised of individuals from different disciplines should approach the care of patients with chronic health conditions. ${ }^{48}$ It identifies the components of care that are relevant to transfer. The CCM also identifies the major barriers to a successful transfer including a lack of coordination between adult and paediatric services, a lack of planning and resistance of patient and families to transition of their healthcare. These themes were also identified in the UK survey on transition care among paediatric and adult gastroenterologists involved in care of AYPs. ${ }^{1}$ A description of the application of this model to a paediatric liver transplant population has been published and illustrates how a theoretical framework can be applied to implement organisational change. ${ }^{49}$

In a systematic review of practices that promote continuity between child and adult services, recurring themes within the literature were identified from which core principles of transition could be established. From this, four models of transition were outlined (direct, sequential, developmental and professional). ${ }^{50}$ In the 'direct' model, the focus is primarily on relations between services and addresses continuity of information between them, rather than focusing on the AYPs' personal growth and development. The 'sequential' model is more flexible and recognises that the AYPs' needs are changing and that they require some preparation if they are to adjust to adult care successfully. A 'developmental' transitional model starts from the premise that the AYP will need some help in acquiring the skills and support systems necessary to use or experience adult care effectively, with an active focus on personal growth and development. Finally, in contrast to the other models, the 'professional' model focuses on the expertise from within one service type (adult or paediatric) and not on the AYP. This may be important in conditions with a short life expectancy or where expertise is heavily located within one service, for example, cystic fibrosis, so is less applicable to chronic GI disease. These models are not mutually exclusive with this guideline reflecting aspects of all of these models in our recommendations but no evidence to support a particular type exclusively.

\section{Recommendation}

We suggest that while there are numerous models of transition there is no evidence to support a particular type (GRADE recommendation: weak (C)).

\section{Essential components of AYP transition clinics}

It is important to design the transition process to be flexible and dependent on patient factors including chronological age, current disease activity, adherence with medical therapies, views of AYP, view of the parents/carers and self-advocacy skills of the patient. The crucial role of a named transition coordinator (eg, for patients with IBD the paediatric IBD nurse who will remain a constant contact and organise the transition process) is a recurring theme in the literature and often scored as the key component of the programme in many surveys. 3335465152

A systematic review of transition services between paediatric and adult healthcare identified three core areas that require attention when developing a successful transition service. These comprised interventions aimed at staffing requirements (transition coordinator) and service delivery (separate young adult clinics, out-of-hours telephone support and enhanced follow-up) and patients (educational programmes and skills training). ${ }^{33}$

\section{AYP transition coordinator}

The AYP transition coordinator is frequently a specialist nurse, often, but not exclusively based within the paediatric service. ${ }^{5354}$ However, an expanded role of the transition coordinator has also been described and applied to patients who have undergone liver transplantation. ${ }^{55}$ In this model, the transition coordinator continues to work with the patients after transfer to the adult services to help address gaps identified in the patients' healthcare management.

\section{Assessment of readiness to transfer}

Several tools that assess the readiness to transfer have been described some of which are disease-specific. ${ }^{56-61}$ The Transition Readiness Assessment Questionnaire is a generic tool that has a high internal consistency and validity. ${ }^{60}$ The University of North Carolina TR(x)ANSITION Scale is a tool for assessing the effectiveness of a transition process. ${ }^{57}$ It uses a semistructured interview with the patient with use of the medical records to verify data. It has a high inter-rater reliability. These tools tend to focus on patients' knowledge of disease and skills. Psychometric data are not frequently collected. Data demonstrating the ability of these tools to predict outcomes of transition are lacking. ${ }^{62}$ The involvement of parents who can 
overestimate AYP self-efficacy ${ }^{63}$ and have higher levels of anxiety than the AYP is deemed important. ${ }^{64}$

\section{Disease-specific education programmes}

A number of tools may be used to facilitate disease education for transitioning patients. The 'IBD passport' (a wallet-sized card containing personal and medical information about the patient) has been identified as such a tool for transitioning AYPs with IBD $^{65}$ by identifying the areas of weakness in which AYPs and parents require education and support such as awareness of disease pathogenesis, disease location, characteristics, medications and health resources available to them. In a pilot study of a disease-specific education programme in liver transplant recipients, a two-session education programme was associated with improvements in adherence to immunosuppressant medications and a reduction in elevated alanine aminotransferase (ALT) levels. ${ }^{49}$ In the first session, the focus was on educating the patient and parents on their disease and the medication regimens necessary to achieve disease control, while the second session focused on practical aspects of taking responsibility for one's care in relation to taking medications, scheduling appointments, communicating directly to healthcare providers and attending appointments alone.

The use of education programmes to facilitate the transition process has been described in other chronic conditions. Disease-specific education programmes and skills training have been associated with improvement in HbA1c, acute complications, self-management skills and disease-specific knowledge in patients with diabetes transitioning to the adult services. ${ }^{66}$ However, no improvement in quality-of-life scores was demonstrated. In patients with juvenile idiopathic arthritis, an age-adjusted structured transition programme that featured a disease-specific programme of education was associated with an improvement in disease-specific quality of life and continuous improvements in knowledge of patients and their parents. ${ }^{36} \mathrm{No}$ impact was demonstrated on independent health behaviours.

Furthermore, disease education for HCPs is a vital component of successful transition. A survey of adult and paediatric gastroenterologists in IBD identified suboptimal training in adolescent care in $65 \%$ and $59 \%$ respectively as a barrier to successful transition. ${ }^{1}$

\section{Recommendation}

We recommend an effective transition model (figure 1) may benefit from inclusion of the following elements (GRADE recommendation: strong (D)):

A. flexible timing of transition

B. a named transition coordinator to oversee the process

C. individualisation of the transition model based on local expertise, staffing, resources and geography

D. assessment of readiness for transfer

E. disease-specific education programme.

We have suggested a transition pathway (figure 2) within this guideline incorporating many of the recommendations and practice points into a practical overview. ${ }^{67}$

\section{Use of technology in AYP transition programmes}

Recent studies ${ }^{35} 4068$ have highlighted the impact and interest in web-based and mobile technologies to assist in the transition process. Such technologies offer several unique advantages including potential for individualisation of the health message being delivered, anonymity, rapid access, low cost and ability to overcome most geographical barriers. With wireless technologies

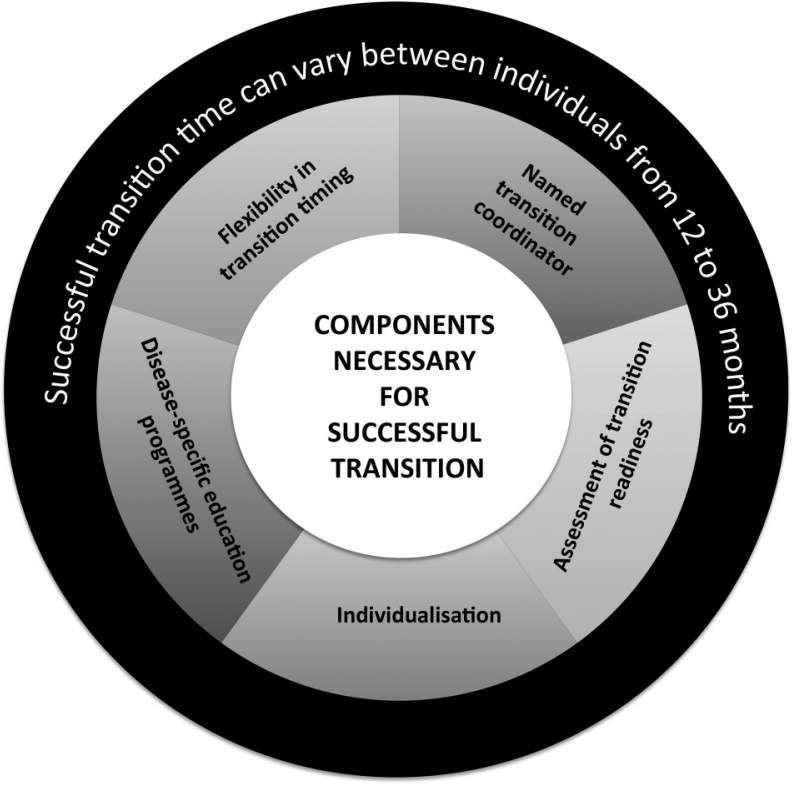

Figure 1 Diagrammatic illustration of the different components an effective transition model should include.

now being ubiquitous and text messaging being one of the main forms of communication by adolescents today, we suggest that such technology should be incorporated into the design of transition models to enable good, rapid communication with health providers for reporting of symptoms, obtaining essential medications, ensuring appointments are not missed, as well as providing links to educational materials and useful websites and support forums. In AYP with type I diabetes, the use of mobile phone interventions have resulted in improved clinic attendance, supported intensive insulin regimens and reduced progression from ketosis to diabetic ketoacidosis in those with poor glycaemic control. ${ }^{69-71}$

A transition intervention for chronic disease (MD2Me) has been tested in a number of chronic diseases including IBD. ${ }^{40}$ This intervention uses technology-based communication between the healthcare team and patients (web-based and text message-based intervention) to enhance access to the healthcare team and to provide disease management and skills-based interventions. In a randomised controlled trial, this has been shown to improve health-related self-efficacy, performance of disease management tasks and patient-initiated communications. However, no beneficial impact was demonstrated for quality-of-life measure, functional performance or for disease status.

\section{Recommendations}

We recommend information technology as an effective and costefficient tool to facilitate transition (GRADE recommendation: strong (C)).

We recommend that AYP's self-efficacy is enhanced by the use of virtual intervention and electronic communication (GRADE recommendation: strong $(\mathrm{C})$ ).

\section{Audit of transition programmes and research into their impact}

In view of the inability to recommend one specific transition model for any specific service, we suggest regular clinical audit of the transition process to identify weaknesses and facilitate 
DETERMINING THE TIMING OF TRANSITION

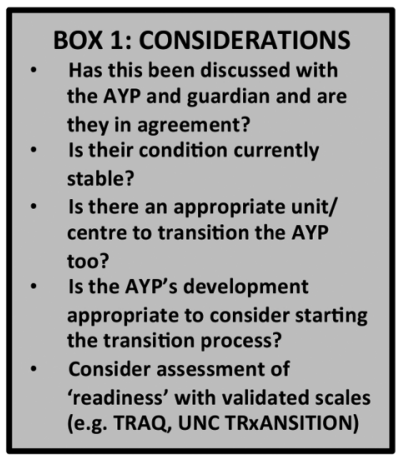

\section{PLANNING FOR TRANSITION}

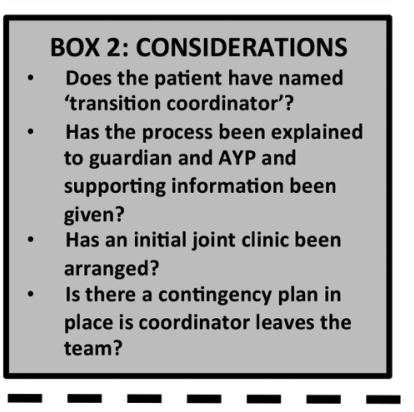

DURING TRANSITION

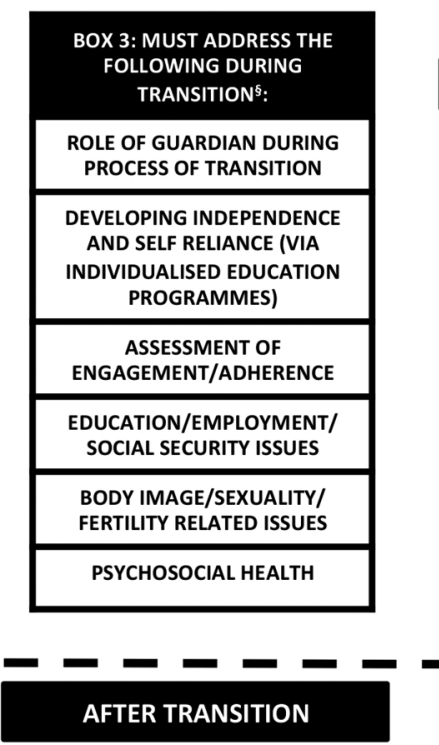

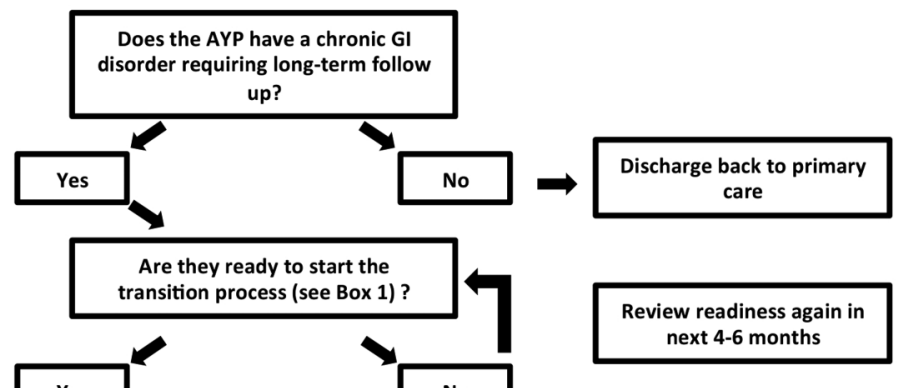

improvements in the process for the benefit of HCPs, patients and carers alike. This would benefit from agreeing on key performance indicators for transition generally that are then complemented by disease-specific indicators. Audit should include assessment of the number of eligible patients that access a transition programme in addition to an assessment of the impact of the programme and patient satisfaction. The impact can be assessed using validated measures of disease-related knowledge and tools that assess progress through the transition process. Research into the impact of a successful transition 
programme is also required, which may include standard transition workshops that take place prior to and during the transition process. ${ }^{72}$ The rate of hospital admissions, use of support services, attendance at outpatient clinic appointments, requirement for steroids, adherence to medications and patient satisfaction would all be potential outcome measures for assessment of the impact of a transition intervention. ${ }^{67}$ Qualitative studies that assess the outcome of transition from a patient and parent perspective are also important. It is unlikely that a controlled trial in this area will be performed due to methodological difficulties in designing an appropriate trial as well as ethical concerns of allocating a group of patients to 'no transition' when all expert consensus suggests that this is inferior. Therefore, it is likely that research will assess outcomes between centres that offer transition compared with those that do not. This will always suffer from bias.

\section{Recommendation}

We recommend regular audit of the transition service in order to improve the service, outcomes and assess key performance indicators (GRADE recommendation: strong (D)).

\section{PATIENT AND CARER/PARENT PERSPECTIVE IN AYP TRANSITION}

\section{Addressing patient and carers/parents readiness during transition}

Anticipation of the timing of transition for AYPs has been identified as one of the most important factors for its success. ${ }^{73} 74$ AYPs with non-GI chronic disease report frustration at inflexibility regarding a determined age of transfer. ${ }^{75}{ }^{76}$ In a study of 28 AYPs with a variety of chronic conditions, AYPs did not identify self-management as an indicator of readiness for transition and some transition occurred before they were willing, or understood the need. ${ }^{77}$ In patients with cystic fibrosis up to 12 months post transition, AYPs felt that paediatric HCPs were more concerned with the clinical parameters than the emotional factors associated with transition, reporting feeling neglected in this period while waiting for the move and being uncertain as to who was responsible for their healthcare needs during this period. $^{78}$

\section{Patient and carer/parents uncertainty and behaviour during transition}

AYPs with IBD may feel a sense of abandonment or be uncertain regarding transfer to adult care ${ }^{79}$ while parents often feel a sense of anxiety about joining a new healthcare team that may not have been adequately informed about their condition. ${ }^{62} 7580$ Furthermore, failure to connect with an adult healthcare provider post transition has been demonstrated to predict future complications in diabetic patients. ${ }^{81}$

AYPs often face multiple transitions (education, employment) at this stage in their lives, which may take priority over their healthcare transition resulting in anxiety and uncertainty. ${ }^{78}$ In this context, AYP may display regressive behaviour during transition $^{82}$ and as a result transition services should identify this and provide supporting emotional and psychological support. Age, gender or severity of disease does not predict level of concern about transition in cystic fibrosis AYPs and their carers/ parents. $^{64}$

The combination of difficult symptoms and use of medications with significant side effects such as corticosteroids results in adolescents with IBD reporting poorer quality of life and an increased prevalence of psychological distress and depression. ${ }^{83} 84$ The most common coping strategy employed by AYP is 'avoidant coping'; where an individual distracts himself or herself with social diversion. ${ }^{85}$ This behaviour is associated with disease relapse in adolescents. ${ }^{86} \mathrm{~A}$ number of studies show improvement in adolescents overall psychological well-being with psychological interventions indicating an important role for the psychologist in IBD. ${ }^{87}$

\section{Recommendation}

We suggest that HCPs consider concerns of AYP and their carers/parents during transition and identify when additional emotional and psychological support is required (GRADE recommendation: weak (D)).

\section{Empowering AYPs self-management: the role of the patient and carers/parents}

Carers/parents of AYP undergoing transition may find it difficult to cope with their reduced role in medical care and should be actively included where appropriate. ${ }^{78} 88$ Carer/parent protectiveness has been reported as a significant challenge in transition in patient with juvenile idiopathic arthritis. ${ }^{89}$ Furthermore, HCPs may perceive AYPs ready to been seen independent of their carers/parents at an earlier age than their carers/parents do. ${ }^{90}$ Negotiating the appropriate level of protectiveness with carer/parent should be based on the AYPS self-efficacy and is an important skill for HCPs to appreciate. ${ }^{50}$

Addressing motivational issues, teaching problem-solving skills and addressing problematic patterns of family functioning are more likely to benefit individuals displaying intentional nonadherence. $^{91}{ }^{92}$ AYPs displaying non-adherence may benefit from more frequent appointments, with intensified clinical interventions. ${ }^{55}$

\section{RECOMMENDATIONS}

We suggest that HCPs maintain the goal of empowering the AYP to become independent while acknowledging the carer/parent perspectives (GRADE recommendation: weak (C).

We recommend that AYPs identified as at risk of non-adherence may benefit from targeted specific educational and organisational interventions (GRADE recommendation: strong $(\mathrm{C})$ ).

\section{Disease-specific information appropriate for developmental age and gender}

Disease-specific knowledge is an important part of AYP transition but information given is not always pertinent to AYPs stage of development, ${ }^{89} 93$ with information more often geared towards the carers/parents rather than AYPs. ${ }^{94}$ AYPs are taking over self-management later than expected from carers/parents, ${ }^{95}$ with those $>18$ years often requiring significant assistance from carers/parents to book clinic appointments and order medications. ${ }^{96}$ Furthermore, the age of disease onset and timing of medical interventions may play a role in mastery over healthcare responsibilities. In liver transplantation, younger male recipients struggled more with mastery over their healthcare compared with those transplanted at an older aged and to females in any age group. ${ }^{97}$

An organised transition programme should include agespecific educational components to address the deficits in AYP knowledge. ${ }^{98}$ Acquisition of skills needed for successful transition should be a stepwise or age appropriate checklist for the AYP. $^{52} 7499100$ In IBD, a 'transition protocol' has been developed by Hait et al, ${ }^{7}$ which is based around developmental milestones to anticipate the changes and normal expectations for AYP for self-management and self-efficacy whereby at different ages (11-13, 14-16, 17-19 and 20-23 years old) a checklist 
of tasks for the medical team (eg, at 11-13 years old, HCP introduces concept of future independent visits to the HCP) and milestones for the AYP (eg, 14-16 years old, AYP knows their own medical history) are gradually obtained on the protocol. However, this does not recognise the variable rate for maturity and developmental milestones, with its inflexible format being its major limitation.

\section{RECOMMENDATION}

We recommend that disease-specific information and education be appropriate for the AYPs developmental stage and this should be reassessed over the period of transition (GRADE recommendation: strong $(\mathrm{C})$ ).

\section{Lifestyle, psychosocial health and sexuality}

Studies in transplant recipients demonstrate that AYPs wish to be treated as adults and prefer healthcare professionals to address them instead of their parents. In addition, these studies have identified that areas that may not be addressed in a paediatric setting such as sexual relationships and recreational drug use are important to AYPs, but they are often reluctant to ask for such information. ${ }^{2180} 101$

AYPs are often concerned that their illness will compromise their employment and preclude them from valued jobs. In a qualitative study of cystic fibrosis and congenital heart disease, AYPs and their carers/parents describe seeing the future as uncertain, with particular concern regarding deteriorating health and occupational restrictions in the future. Employment issues are one of the primary sources of stress for cystic fibrosis AYPs in transition. ${ }^{102}$

AYPs with GI disease report major concerns regarding body image and HCPs may encounter resistance to the use of corticosteroids in the transition period ${ }^{103}$ AYPs with IBD also describe concerns relating to future fertility ${ }^{104}$ and a sense of potential loss regarding normal gendered roles such as motherhood. ${ }^{102}$ Similarly AYPs with juvenile idiopathic arthritis express concern over disclosing illness to sexual partners. ${ }^{89} 105$ Furthermore, AYPs' liver transplant recipients express concern about transmitting illness to descendants with concern regarding immunosuppression on fertility and future children's health and demonstrating a lack of understanding of genetic risk. ${ }^{106}$ Furthermore, AYPs may not feel doctors understand the wider impact on their life. ${ }^{89} 105$

\section{Recommendation}

We suggest the transition process addresses the AYP's lifestyle, future health concerns, educational/employment goals, psychosocial health, sexuality and reproduction (GRADE recommendation: weak (D)).

\section{SURGICAL PERSPECTIVE}

There is limited data in relation to transition of AYP in the field of surgery. There are several groups of patients that may benefit from transition from paediatric to adult care:

1. Patients who have undergone surgery in a specialist paediatric unit who require long-term follow-up and have reached an age where care in a paediatric setting is no longer inappropriate.

2. Patients who have been receiving ongoing paediatric medical treatment for a condition requiring surgical intervention at an age on the cusp of needing transition to an adult surgical service.
3. Patients with newly diagnosed conditions needing surgical intervention diagnosed at an age where transition to an adult service is indicated.

While it would be possible for AYPs in the above groups to be seen in a regular adult surgical outpatient setting, this would require initiating a new dialogue with the adult surgeon. AYPs and parents/carers may find the adult clinic setting an intimidating experience compared with the more familiar paediatric environment.

In a surgical gastroenterological transition clinic, the paediatric surgeon can hand the case over to his adult surgeon colleague. This may entail not only describing in detail the procedures already performed by the paediatric surgeon but also the nuances around any family dynamics and aspects of the patients psyche. This will enable robust transfer of anatomical surgical knowledge and engendering confidence in the receiving surgeon, AYP and parent/carers. In specific cases, it may also be appropriate for the adult surgeon to consider operating jointly with the paediatric surgeon if the AYP is not yet ready for transition.

\section{Practice point}

- We suggest that AYPs who require surgical intervention during the transition period have a named adult surgeon in the disciplined concerned involved in their care preoperatively, perioperatively and postoperatively, and that surgeon will form part of the multidisciplinary team in transition care.

\section{CONCLUSION}

This guideline provides the framework for healthcare professionals to develop transition services for patients with chronic GI disorders, using the best available research data from the literature related to AYPs with GI disorders and other chronic disorders in which transition between paediatric and adult health services is routinely done. The most significant limitation of this review is that the recommendations are predominantly based on evidence graded as weak due to the paucity of randomised controlled trials in this area. In addition, there is a significant lack of GI-specific data in this expanding field and hence recommendations are based on evidence not exclusively pertainable to GI-specific research. Future studies are needed to improve the strength of recommendations for future revisions of the guidelines. Furthermore, future research must consider design to improve outcome-based data with longitudinal design in order to aid future cost-benefit analysis to be undertaken. Our hope is that this guideline will stimulate more GI-related research in this field so future revisions will be supported by an expanding robust and broad evidence base.

\section{SCHEDULED REVIEW OF GUIDELINES}

The proposed date for review is 1 August 2021 to take account new developments in this area and as set out in the 'BSG Guideline Advice' document. ${ }^{5}{ }^{6}$ Every two years the research objectives identified in the guidelines will be reviewed for evidence of additional studies, which may contribute to resolving the objectives. The guidelines are available on the BSG website (http://www.bsg.org.uk) and listed by date of publication. These guidelines are accessible to the public. There is a forum for feedback from BSG members via the forum link in the members' area on the BSG website to ensure there is a facility for feedback after publications. Any publication updates maybe published in Gut as a letter subject to the normal review processes of the journal and are submitted to the CSSC Secretary/Guidelines 
Editor who arranges a peer review by the CSSC prior to submission to Gut.

\section{Author affiliations}

${ }^{1}$ Academic Department of Gastroenterology, Sheffield Teaching Hospitals NHS Foundation Trust, Royal Hallamshire Hospital, Sheffield, UK

${ }^{2}$ Centre for Gastroenterology and Hepatology, Royal Free Hospital, London, UK

${ }^{3}$ Department of Surgery, UCLH, London, UK

${ }^{4}$ Royal Liverpool University Hospital, Liverpool, UK

${ }^{5}$ Queen Elizabeth Hospital NHS Foundation Trust, University of East Anglia, King's Lynn, Norfolk, UK

${ }^{6}$ Sheffield Children's Hospital NHS Foundation Trust, Sheffield, UK

${ }^{7}$ Glasgow Royal Infirmary, Glasgow, UK

${ }^{8}$ Deparment of Gastroenterology, Royal Victoria Hospital, Belfast, UK

${ }^{9}$ Liver Unit, Birmingham Children's Hospital, Birmingham, UK

${ }^{10}$ NIHR LCRN (Y\&H) Gastroenterology Speciality Co-Lead, Hull \& East Yorkshire NHS Trust, Hull, UK

${ }^{11}$ Queen Elizabeth Hospital Birmingham NHS Foundation Trust, Birmingham, UK

${ }^{12} \mathrm{GI}$ Services Division, University College London Hospital, London, UK

${ }^{13}$ London, UK

${ }^{14}$ Department of Paediatric Gastroenterology, The Royal Hospital for Children Glasgow, Glasgow, UK

${ }^{15}$ Department of Gastroenterology, UCLH, London, UK

${ }^{16}$ Bart's Health NHS Trust, The Royal London Hospital, London, UK

${ }^{17}$ Centre for Immunology and Infectious Disease, Blizard Institute, Barts and the London School of Medicine, Queen Mary University of London, London, UK

Twitter Follow Alenka Brooks@alenkabrooks and Philip Smith @drphilipjsmith

Acknowledgements BSG Adolescent and Young Person Section 2013-2015, Ms Simone Cort, a BSG staff member who provided invaluable assistance with guideline production. The authors like to thank Mrs Sarah Macdonald, Principal Dietician and Team Leader, Great Ormond Street Hospital for Children NHS Trust, and Mr Richard Fallis, Subject Librarian for Medicine, Dentistry and Biomedical Sciences, at Queen's University Belfast for their input. The authors would also like to thank Mr Elliot James, who represented Crohn's and Colitis UK (CCUK) as well as members of Core and Crohn's in Childhood Research Association (CICRA) for their collaboration and input into this guideline.

Contributors PJS, AJB, SAM and JOL wrote and revised the manuscript, devised figures 1, 2 and tables 2, 3, and were part of the working group that developed the recommendations. RC, PC, AD, VF, DRG, RKR, SS, LWh, MS, BTJ, PJM, CDM and LWi also contributed to the manuscript and helped develop the recommendations. Table 1 was developed by RKR, AD and PJM.

Funding This guideline was commissioned by Clinical Services and Standards Committee (CSSC) of the British Society of Gastroenterology (BSG) under the auspices of the Adolescent \& Young Person Section of the BSG.

Competing interests JOL was a member of Clinical Trials Research Group of the BSG 2014-2016, Chair of Education Committee ECCO 2014-2016, Editorial Board CCUK 2014-2016. RKR was a Medical Advisor of CCUK from 2013 to 2016; and LW was a Nurse Reader for information leaflets for CCUK from 2012 to 2016.

Provenance and peer review Not commissioned; externally peer reviewed.

Open Access This is an Open Access article distributed in accordance with the Creative Commons Attribution Non Commercial (CC BY-NC 4.0) license, which permits others to distribute, remix, adapt, build upon this work non-commercially, and license their derivative works on different terms, provided the original work is properly cited and the use is non-commercial. See: http://creativecommons.org/ licenses/by-nc/4.0/

\section{REFERENCES}

1 Sebastian $S$, Jenkins $H$, Mccartney $S$, et al. The requirements and barriers to successful transition of adolescents with inflammatory bowel disease: differing perceptions from a survey of adult and paediatric gastroenterologists. J Crohns Colitis 2012:6:830-44

2 Houston $\mathrm{Y}, \mathrm{O}$ Lindsay J, Jenkins $\mathrm{H}$, et al. Perspectives of transition care in inflammatory bowel disease: a survey. Gastrointest Nurs 2012;10:30-5.

3 Elli L, Maieron R, Martelossi S, et al. Transition of gastroenterological patients from paediatric to adult care: A position statement by the Italian Societies of Gastroenterology. Dig Liver Dis 2015;47:734-40.

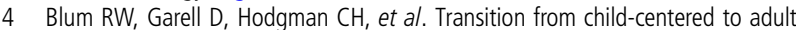
health-care systems for adolescents with chronic conditions. A position paper of the Society for Adolescent Medicine. J Adolesc Health 1993;14:570-6.

5 Tham TCK, Gleeson D, Greenfield SM, et al. British Society of Gastroenterology policy and processes for the development of guidelines. Gut 2015;64:1184-5.
6 BSG. Advice on the production of guidelines British Society of Gastroenterology advice on the production of guidelines. 2016 (cited 23 Aug 2016). http://www. bsg.org.uk/clinical-guidelines/general/advice-on-the-production-of-guidelines.htm

7 Guyatt G, Oxman AD, Akl EA, et al. GRADE guidelines: 1. Introduction-GRADE evidence profiles and summary of findings tables. J Clin Epidemiol 2011;64:383-94.

8 Guyatt $\mathrm{GH}, \mathrm{Oxman} A D$, Vist GE, et al. GRADE: an emerging consensus on rating quality of evidence and strength of recommendations. BMJ 2008:336:924-6.

9 Brouwers MC, Kho ME, Browman GP, et al. Development of the AGREE II, part 2: assessment of validity of items and tools to support application. CMAJ 2010;182: E472-8.

10 Ruemmele FM, Veres $\mathrm{G}$, Kolho $\mathrm{KL}$, et al. Consensus guidelines of ECCO/ESPGHAN on the medical management of pediatric Crohn's disease. J Crohns Colitis 2014:8:1179-207.

11 Turner D, Levine A, Escher JC, et al. Management of pediatric ulcerative colitis: joint ECCO and ESPGHAN evidence-based consensus guidelines. J Pediatr Gastroenterol Nutr 2012;55:340-61.

12 Muhammed $\mathrm{R}$, Jenkins $\mathrm{H}$. Transition clinics in paediatric gastroenterology in the United Kingdom: room for improvement. J Pediatr Gastroenterol Nutr. 2010;51:242.

13 Davies IH, Jenkins HR. Transition clinics for adolescents with chronic gastrointestinal disease in the UK and Ireland. J Pediatr Gastroenterol Nutr 2003:36:505-6.

14 Ludvigsson JF, Agreus L, Ciacci $C$, et al. Transition from childhood to adulthood in coeliac disease: the Prague consensus report. Gut 2016:65:1242-51.

15 Dellon ES, Jones PD, Martin NB, et al. Health-care transition from pediatric to adult-focused gastroenterology in patients with eosinophilic esophagitis. Dis Esophagus 2013;26:7-13.

16 Sood MR, Rudolph CD. Gastrointestinal motility disorders in adolescent patients: transitioning to adult care. Gastroenterol Clin North Am 2007;36:749-63.

17 Williams R, Aspinall R, Bellis $M$, et al. Addressing liver disease in the UK: a blueprint for attaining excellence in health care and reducing premature mortality from lifestyle issues of excess consumption of alcohol, obesity, and viral hepatitis. Lancet 2014;384:1953-97.

18 Annual Report on Liver Transplantation. 2014. http://www.odt.nhs.uk/pdf/organ_ specific_report_liver_2014.pdf

19 Van Limbergen J, Russell RK, Drummond HE, et al. Definition of phenotypic characteristics of childhood-onset inflammatory bowel disease. Gastroenterology 2008; 135:1114-22.

20 Ludvigsson JF, Bai JC, Biagi F, et al. Diagnosis and management of adult coeliac disease: guidelines from the British Society of Gastroenterology. Gut 2014;63:1210-28.

21 Tuchman LK, Slap GB, Britto MT. Transition to adult care: experiences and expectations of adolescents with a chronic illness. Child Care Health Dev 2008;34:557-63.

22 Nakhla M, Daneman D, To T, et al. Transition to adult care for youths with diabetes mellitus: findings from a Universal Health Care System. Pediatrics 2009:124:e1134-41.

23 Kipps S, Bahu T, Ong K, et al. Current methods of transfer of young people with Type 1 diabetes to adult services. Diabet Med 2002;19:649-54.

24 Wray J, Frigiola A, Bull C. Loss to specialist follow-up in congenital heart disease; out of sight, out of mind. Heart 2013;99:485-90.

25 Andemariam B, Owarish-Gross J, Grady J, et al. Identification of risk factors for an unsuccessful transition from pediatric to adult sickle cell disease care. Pediatr Blood Cancer 2014;61:697-701.

26 Annunziato RA, Emre S, Shneider B, et al. Adherence and medical outcomes in pediatric liver transplant recipients who transition to adult services. Pediatr Transplant 2007;11:608-14.

27 Watson AR. Non-compliance and transfer from paediatric to adult transplant unit. Pediatr Nephrol 2000;14:469-72.

28 Cole R, Ashok D, Razack A, et al. Evaluation of outcomes in adolescent inflammatory bowel disease patients following transfer from pediatric to adult health care services: case for transition. J Adolesc Health 2015;57:212-17.

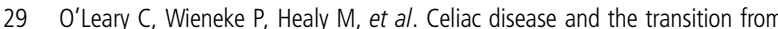
childhood to adulthood: a 28-year follow-up. Am J Gastroenterol 2004:99:2437-41.

30 Calsbeek H, Rijken M, Dekker J, et al. Disease characteristics as determinants of the labour market position of adolescents and young adults with chronic digestive disorders. Eur J Gastroenterol Hepatol 2006;18:203-9.

31 Longobardi T, Jacobs P, Bernstein CN. Work losses related to inflammatory bowel disease in the United States: results from The National Health Interview Survey. Am J Gastroenterol 2003:98:1064-72.

32 Cadario F, Prodam F, Bellone S, et al. Transition process of patients with type 1 diabetes (T1DM) from paediatric to the adult health care service: a hospital-based approach. Clin Endocrinol (Oxf) 2009;71:346-50.

33 Crowley R, Wolfe I, Lock $\mathrm{K}$, et al. Improving the transition between paediatric and adult healthcare: a systematic review. Arch Dis Child 2011;96:548-53. 
34 Holmes-Walker DJ, Llewellyn AC, Farrell K. A transition care programme which improves diabetes control and reduces hospital admission rates in young adults with Type 1 diabetes aged 15-25 years. Diabet Med 2007;24:764-9.

35 Van Walleghem N, Macdonald CA, Dean HJ. Evaluation of a systems navigator model for transition from pediatric to adult care for young adults with type 1 diabetes. Diabetes Care 2008;31:1529-30.

36 McDonagh JE, Southwood TR, Shaw KL. The impact of a coordinated transitional care programme on adolescents with juvenile idiopathic arthritis. Rheumatology 2007:46:161-8

37 Mackie AS, Islam S, Magill-Evans J, et al. Healthcare transition for youth with heart disease: a clinical trial. Heart 2014;100:1113-18.

38 Harden PN, Walsh G, Bandler N, et al. Bridging the gap: an integrated paediatric to adult clinical service for young adults with kidney failure. BMJ 2012;344: e3718.

39 Dabadie A, Troadec F, Heresbach D, et al. Transition of patients with inflammatory bowel disease from pediatric to adult care. Gastroentérologie Clin Biol 2008;32:451-9.

40 Huang JSS, Terrones L, Tompane T, et al. Preparing adolescents with chronic disease for transition to adult care: A technology program. Pediatrics 2014;133: e1639-46.

41 Fredericks EM, Dore-Stites D, Well A, et al. Assessment of transition readiness skills and adherence in pediatric liver transplant recipients. Pediatr Transp/ 2010;14:944-53.

42 Annunziato RA, Baisley MC, Arrato N, et al. Strangers headed to a strange land? A pilot study of using a transition coordinator to improve transfer from pediatric to adult services. J Pediatr 2013;163:1628-33.

43 McDonagh JE. Transition of care from paediatric to adult rheumatology. Arch Dis Child 2007;92:802-7.

44 Sawyer SM, Blair S, Bowes G. Chronic illness in adolescents: transfer or transition to adult services? J Paediatr Child Health 1997;33:88-90.

45 Remorino R, Taylor J. Smoothing things over: the transition from pediatric to adult care for kidney transplant recipients. Prog Transp/ 2006;16:303-8.

46 Doug M, Adi Y, Williams J, et al. Transition to adult services for children and young people with palliative care needs: a systematic review. Arch Dis Child 2011;96:78-84.

47 El-Matary W. Transition of children with inflammatory bowel disease: big task, little evidence. World J Gastroenterol 2009;15:3744-7.

48 Hroscikoski MC, Solberg LI, Sperl-Hillen JM, et al. Challenges of change: a qualitative study of chronic care model implementation. Ann Fam Med 2006;4:317-26

49 Annunziato RA, Emre S, Shneider BL, et al. Transitioning health care responsibility from caregivers to patient: a pilot study aiming to facilitate medication adherence during this process. Pediatr Transplant 2008;12:309-15.

50 While A, Forbes A, Ullman R, et al. Good practices that address continuity during transition from child to adult care: synthesis of the evidence. Child Care Heal Dev 2004;30:439-52.

51 Goodhand J, Hedin CR, Croft NM, et al. Adolescents with IBD: the importance of structured transition care. J Crohns Colitis 2011;5:509-19.

52 Leung Y, Heyman MB, Mahadevan U. Transitioning the adolescent inflammatory bowel disease patient: guidelines for the adult and pediatric gastroenterologist. Inflamm Bowel Dis 2011;17:2169-73.

53 Pywell A. "Transition: moving on well" — from paediatric to adult health care. Br J Nurs 2010;19:652-6.

54 Rapley P, Davidson PM. Enough of the problem: a review of time for health care transition solutions for young adults with a chronic illness. J Clin Nurs 2010;19:313-23.

55 Annunziato RA, Hogan B, Barton C, et al. A translational and systemic approach to transferring liver transplant recipients from pediatric to adult-oriented care settings. Pediatr Transplant 2010;14:823-9.

56 Cappelli M, MacDonald NE, McGrath PJ. Assessment of readiness to transfer to adult care for adolescents with cystic fibrosis. Child Health Care 1989;18:218-24.

57 Ferris ME, Harward DH, Bickford K, et al. A clinical tool to measure the components of health-care transition from pediatric care to adult care: the UNC TR (x)ANSITION scale. Ren Fail 2012;34:744-53.

58 Gilleland J, Amaral S, Mee L, et al. Getting ready to leave: transition readiness in adolescent kidney transplant recipients. J Pediatr Psychol 2012;37:85-96.

59 Paone MC, Wigle M, Saewyc E. The ON TRAC model for transitional care of adolescents. Prog Transp/ 2006;16:291-302.

60 Sawicki GS, Lukens-Bull K, Yin X, et al. Measuring the transition readiness of youth with special healthcare needs: validation of the TRAQ_-Transition Readiness Assessment Questionnaire. J Pediatr Psychol 2011;36:160-71.

61 Wood DL, Sawicki GS, Miller MD, et al. The Transition Readiness Assessment Questionnaire (TRAQ): its factor structure, reliability, and validity. Acad Pediatr 2014; 14:415-22.

62 Schwartz LA, Daniel LC, Brumley LD, et al. Measures of readiness to transition to adult health care for youth with chronic physical health conditions: a systematic review and recommendations for measurement testing and development. J Pediatr Psychol 2014;39:588-601.
63 Zijlstra M, De Bie C, Breij L, et al. Self-efficacy in adolescents with inflammatory bowel disease: a pilot study of the "IBD-yourself", a disease-specific questionnaire. J Crohns Colitis 2013;7:e375-85.

64 Boyle MP, Farukhi Z, Nosky ML. Strategies for improving transition to adult cystic fibrosis care, based on patient and parent views. Pediatr Pulmonol 2001;32:428-36.

65 Benchimol El, Walters TD, Kaufman M, et al. Assessment of knowledge in adolescents with inflammatory bowel disease using a novel transition tool. Inflamm Bowel Dis 2011;17:1131-7.

66 Vidal M, Jansa M, Anguita C, et al. Impact of a special education programme in patients transferred from a paediatric to an adult diabetes unit. Eur Diabetes Nurs 2004:1:23-7.

67 Transition from children's to adults' services for young people using health or social care services. http://nice.org.uk/guidance/ng43

68 McKenzie RB, Berquist WE, Foley MA, et al. Text Messaging Improves Participation in Laboratory Testing in Adolescent Liver Transplant Patients. J Particip Med 2015;7:e7.

69 Franklin V, Waller A, Pagliari C, et al. "Sweet Talk": text messaging support for intensive insulin therapy for young people with diabetes. Diabetes Technol Ther 2003;5:991-6

70 Downer SR, Meara JG, Da Costa AC. Use of SMS text messaging to improve outpatient attendance. Med J Aust 2005;183:366-8.

71 Farrell K, Holmes-Walker DJ. Mobile phone support is associated with reduced ketoacidosis in young adults. Diabet Med 2011;28:1001-4.

72 Schmidt S, Herrmann-Garitz C, Bomba F, et al. A multicenter prospective quasi-experimental study on the impact of a transition-oriented generic patient education program on health service participation and quality of life in adolescents and young adults. Patient Educ Couns 2016;99:421-8.

73 McDonagh JE. Growing up and moving on: transition from pediatric to adult care. Pediatr Transp/ 2005;9:364-72.

74 Hait E, Arnold JH, Fishman LN. Educate, communicate, anticipate-practical recommendations for transitioning adolescents with IBD to adult health care. Inflamm Bowel Dis 2006;12:70-3.

75 Brumfield K, Lansbury G. Experiences of adolescents with cystic fibrosis during their transition from paediatric to adult health care: a qualitative study of young Australian adults. Disabil Rhabil 2004;26:223-34.

76 Busse FP, Hiermann P, Galler A, et al. Evaluation of patients' opinion and metabolic control after transfer of young adults with type 1 diabetes from a pediatric diabetes clinic to adult care. Horm Res 2007;67:132-8.

77 Beresford B, Stuttard L. Young adults as users of adult healthcare: experiences of young adults with complex or life-limiting conditions. Clin Med 2014;14:404-8.

78 Tierney S, Deaton C, Jones A, et al. Liminality and transfer to adult services: a qualitative investigation involving young people with cystic fibrosis. Int J Nurs Stud 2013:50:738-46.

79 de Silva PSA, Fishman LN. Transition of the patient with IBD from pediatric to adult care-an assessment of current evidence. Inflamm Bowel Dis 2014;20:1458-64.

80 McCurdy C, DiCenso A, Boblin S, et al. There to here: young adult patients' perceptions of the process of transition from pediatric to adult transplant care. Prog Translant 2006;16:309-16.

81 Bryden KS, Dunger DB, Mayou RA, et al. Poor prognosis of young adults with type 1 diabetes: a longitudinal study. Diabetes Care 2003;26:1052-7.

82 Adamiak T, Walkiewicz-Jedrzejczak D, Fish D, et al. Incidence, clinical characteristics, and natural history of pediatric IBD in Wisconsin: a population-based epidemiological study. Inflamm Bowel Dis 2013;19:1218-23.

83 Szigethy $E$, Craig $A E$, lobst EA, et al. Profile of depression in adolescents with inflammatory bowel disease: implications for treatment. Inflamm Bowel Dis 2009;15:69-74.

84 Szigethy $E$, Levy-warren A, Whitton $S$, et al. Depressive symptoms and inflammatory bowel disease in children and adolescents: a cross-sectional study. J Pediatr Gastroenterol Nutr 2004;39:395-403.

85 van der Zaag-Loonen HJ, Grootenhuis MA, Last BF, et al. Coping strategies and quality of life of adolescents with inflammatory bowel disease. Qual Life Res 2004;13:1011-19.

86 Bitton A, Dobkin PL, Edwardes MD, et al. Predicting relapse in Crohn's disease: a biopsychosocial model. Gut 2008;57:1386-92.

87 Szigethy E, Bujoreanu SI, Youk AO, et al. Randomized Efficacy Trial of Two Psychotherapies for Depression in Youth With Inflammatory Bowel Disease. J Am Acad Child Adolesc Psychiatry 2014;53:726-35.

88 Schultz RJ. Parental experiences transitioning their adolescent with epilepsy and cognitive impairments to adult health care. J Pediatr Heal Care 2013:27:359-66.

89 Shaw KL, Southwood TR, McDonagh JE. User perspectives of transitional care for adolescents with juvenile idiopathic arthritis. Rheumatology 2004:43:770-8.

90 Geenen SJ, Powers LE, Sells W. Understanding the role of health care providers during the transition of adolescents with disabilities and special health care needs. $J$ Adolesc Heal 2003;32:225-33. 
91 Hommel KA, Hente EA, Odell S, et al. Evaluation of a group-based behavioral intervention to promote adherence in adolescents with inflammatory bowel disease. Eur J Gastroenterol Hepatol 2012;24:64-9.

92 Greenley RN, Kunz JH, Walter J, et al. Practical strategies for enhancing adherence to treatment regimen in inflammatory bowel disease. Inflamm Bowel Dis 2013;19:1534-45

93 Ullrich G, Mattussek S, Dressler F, et al. How do adolescents with juvenile chronic arthritis consider their disease related knowledge, their unmet service needs, and the attractiveness of various services? Eur J Med Res 2002;7:8-18.

94 Berry SL, Hayford JR, Ross CK, et al. Conceptions of illness by children with juvenile rheumatoid arthritis: a cognitive developmental approach. J Pediatr Psychol 1993; 18:83-97.

95 van Groningen J, Ziniel S, Arnold J, et al. When independent healthcare behaviors develop in adolescents with inflammatory bowel disease. Inflamm Bowel Dis 2012;18:2310-14.

96 Fishman LN, Barendse RM, Hait E, et al. Self-management of older adolescents with inflammatory bowel disease: a pilot study of behavior and knowledge as prelude to transition. Clin Paediatr 2010;49:1129-33.

97 Piering K, Arnon R, Miloh TA, et al. Developmental and disease-related influences on self-management acquisition among pediatric liver transplant recipients. Pediat Transp/ 2011;15:819-26.

98 Benchimol El, Fortinsky KJ, Gozdyra P, et al. Epidemiology of pediatric inflammatory bowel disease: a systematic review of international trends. Inflamm Bowel Dis 2011;17:423-39.
99 Lugasi T, Achille M, Stevenson M. Patients' perspective on factors that facilitate transition from child-centered to adult-centered health care: a theory integrated metasummary of quantitative and qualitative studies. J Adolesc Health 2011:48:429-40.

100 Pinzon JL, Jacobson K, Reiss J. Say goodbye and say hello: the transition from pediatric to adult gastroenterology. Can J Gastroenterol 2004; 18:735-42.

101 Stabile L, Rosser L, Porterfield KM, et al. Transfer versus transition: success in pediatric transplantation brings the welcome challenge of transition. Progr Transpl 2005; 15:363-70

102 Moola FJ, Norman ME. "Down the rabbit hole": enhancing the transition process for youth with cystic fibrosis and congenital heart disease by re-imagining the future and time. Child Care Health Dev 2011;37:841-51.

103 Muller KR, Prosser R, Bampton P, et al. Female gender and surgery impair relationships, body image, and sexuality in inflammatory bowel disease: patient perceptions. Inflamm Bowel Dis 2010;16:657-63.

104 van der Woude CJ, Kolacek S, Dotan I, et al. European evidenced-based consensus on reproduction in inflammatory bowel disease. J Crohns Colitis 2010;4:493-510.

105 McDonagh JE. Young people first, juvenile idiopathic arthritis second: Transitional care in rheumatology. Arthritis Rheus 2008;59:1162-70.

106 Aujoulat I, Janssen M, Libion F, et al. Internalizing motivation to self-care: a multifaceted challenge for young liver transplant recipients. Qual Heal Res 2014;24:357-65.

\section{EDITOR'S QUIZ: GI SNAPSHOT}

\section{A rare cause of $\mathrm{Gl}$ bleeding in a 56-year-old man}

A 56-year-old man, with a known history of diabetes for 1 year, presented with a 5-day history of melena that was associated with one episode of haematemesis. One month prior, he had completed a course of oral amoxicillin for a dental infection that occurred after a tooth extraction. The only other significant past medical problem was hypertension for 10 years. Physical examination only showed pallor and abdominal examination was normal. Laboratory investigations revealed haemoglobin level of $8.4 \mathrm{~g} / \mathrm{dL}$ and $\mathrm{HbA} 1 \mathrm{C}$ of $7.8 \%$. His upper GI endoscopy showed a diffuse irregular friable exudative ulcerative lesion involving the gastric fundus (figure 1). Endoscopic ultrasonography (EUS) demonstrated disrupted gastric wall layers with wall thickening of $5.1 \mathrm{~mm}$ and regional lymph nodes (figure 2).
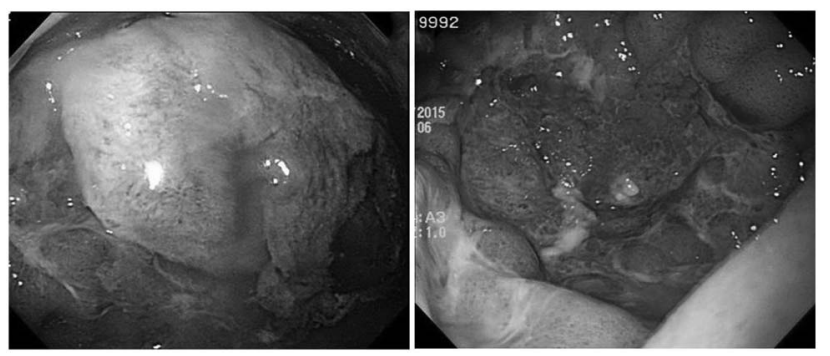

Figure 1 Upper GI endoscopy illustrated diffuse irregular friable exudative ulcerative lesion involving gastric fundus.

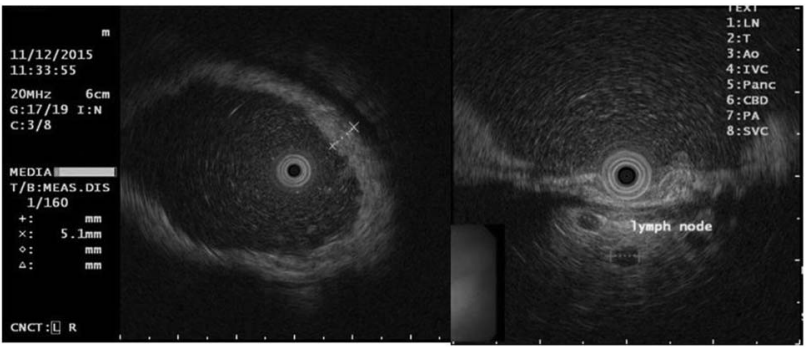

Figure 2 Endoscopic ultrasonography demonstrated disrupted gastric wall layers with regional lymph nodes.

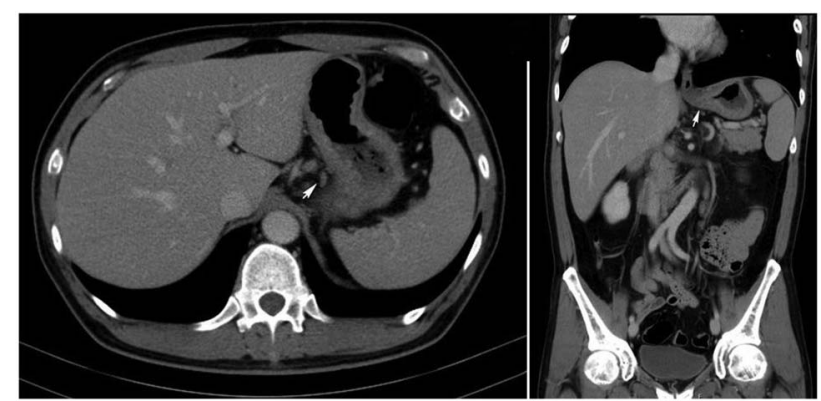

Figure 3 CT showed thickened gastric wall and cluster of regional lymph nodes.

Abdominal CT also showed gastric wall thickening and cluster of regional lymph nodes (figure 3). Upper GI series showed a focal irregular mucosal pattern with relatively flattened gastric fundus.

\section{QUESTION}

What is the most likely diagnosis?

See page 1074 for answer 